\title{
EVALUATION OF ARTERIAL CATHETER MANAGEMENT IN VERY PRETERM NEONATES : PERIPHERAL ARTERY VERSUS UMBILICAL ARTERY
}

\author{
TAKASHI IMAMURA ${ }^{1)}$, NOBUO MOMOI ${ }^{1)}$, HAYATO GO ${ }^{1)}$, KEI OGASAWARA ${ }^{1)}$, \\ YUJI KANAI ${ }^{1)}$, MAKI SATO ${ }^{1)}$, AYA GOTO ${ }^{2)}$ and MITSUAKI HOSOYA ${ }^{1)}$ \\ ${ }^{1)}$ Department of Pediatrics, ${ }^{2}$ Public Health, Fukushima Medical University School of Medicine, Fuku- \\ shima City, Fukushima, Japan
}

(Received September 1, 2011, accepted November 28, 2011)

\begin{abstract}
:
Objectives : To evaluate whether peripheral arterial catheter management is more effective than umbilical arterial management in very preterm neonates.

Methods : Thirty-eight very preterm neonates born in Fukushima Medical University Hospital between October 2008 and March 2010 were evaluated. A peripheral arterial catheter was inserted in 19 neonates (peripheral group) and an umbilical arterial catheter in the remaining 19 neonates (umbilical group).

Results : The median gestational ages of the peripheral and umbilical groups were 195 and 185 days, respectively $(p=0.04)$. The systolic and diastolic blood pressure (BP) was significantly higher in the peripheral group than in the umbilical group $(p=0.03$ and $p=0.001)$. There was a significant relationship between BP at cannulation and urinary output after cannulation for $24 \mathrm{~h}$ in the peripheral group $\left(r_{\mathrm{s}}=0.49, p=0.03\right)$; however, no such significant relationship was found in the umbilical group.

Conclusions : We considered that peripheral artery catheters provide a well-functioning route for continuous BP monitoring, even in very preterm neonates. Because umbilical catheter placement might affect urinary output, we speculated that peripheral arterial catheter placement would be a more effective management strategy than umbilical arterial catheter placement in very preterm neonates. Further studies of larger populations are necessary to evaluate the effectiveness of arterial management including long-term follow-up studies.
\end{abstract}

Key words : peripheral artery, umbilical artery, very preterm neonates

ABBREVIATIONS : BP, blood pressure ; GA, gestational age; BBW, body birth weight; TTTS, twin-to-twin transfusion syndrome; SGA, small for gestational age; CHD, continuous hemodialysis; BT, body temperature; IVH, intraventricular hemorrhage; NICU, neonatal intensive care unit ; UmApH, umbilical artery $\mathrm{pH}$; CAM, chorioamnionitis ; HR, heart rate ; RDS, respiratory distress syndrome ; DOA, dopamine ; HDC, hydrocortisone; PDA, patent ductus arteriosus; NEC, necrotizing enterocolitis; TPN, total parenteral nutrition; CRP, $\mathrm{C}$ reactive protein ; SMA, superior mesenteric artery

\section{INTRODUCTION}

A continuous indwelling arterial catheter is necessary for monitoring blood gases and blood pressure (BP), and it is required for frequent arterial blood sampling to achieve intensive management in

今村 孝, 桃井伸緒, 郷 勇人, 小笠原啓, 金井祐二, 佐藤真紀, 後藤あや, 細矢光亮

Corresponding author : Takashi Imamura, MD, PhD E-mail address : ima@fmu.ac.jp

https://www.jstage.jst.go.jp/browse/fms http://www.fmu.ac.jp/home/lib/F-igaku/ 
very preterm neonates ${ }^{1)}$. There are two methods of arterial catheter management. The umbilical artery is usually cannulated immediately after birth. However, it is inappropriate for neonates with a thin or hypertorsion of umbilical cord, or for those who are several days old. On the other hand, percutaneous catheterization of an artery using transillumination is a rapid, simple and safe method ${ }^{2}$. However, peripheral arteries may be difficult to cannulate because of their small size, vasoconstriction due to hypothermia or hypotension, or multiple previous punctures at the site. To our knowledge, there have been few reports on the evaluation of comparison umbilical and peripheral arterial catheter management in neonates.

The purpose of this study is to evaluate whether peripheral arterial catheter management is more effective than umbilical arterial management in very preterm neonates.

\section{MATERIAL AND METHODS}

\section{Definition}

Arterial catheter insertion is a routine procedure in our hospital for neonates under mechanical ventilation with the following conditions ; 1) the gestational age (GA) is less than 28 weeks and the body birth weight (BBW) is less than $1,000 \mathrm{~g} ; 2$ ) specific conditions such as twin-to-twin transfusion syndrome (TTTS), small for gestational age (SGA), severe hypoxemia, hypoplastic lungs or idiopathic hypertension ; 3) a major anomaly necessitating an emergency operation after birth such as congenital diaphragmatic hernia, intestinal atresia or diastematomyelia ; and 4) the need of a blood access for blood exchange or continuous hemodialysis (CHD). An arterial catheter is used to obtain blood for laboratory analysis and BP monitoring. No medications, additional fluids, electrolytes, or blood products are administered through the line. GA was determined from the last maternal menstrual period, obstetric history and examination, and prenatal ultrasound findings. SGA was defined as BBW under the $10^{\text {th }}$ percentile for GA in accordance with the gender-specific growth charts of Kramer et $a l .{ }^{3)}$. Body temperature (BT) was measured in the anus. Intraventricular hemorrhage (IVH) was diagnosed by ultrasonography and graded in accordance with definitions by Papile et $a l .{ }^{4}$.

\section{Patients}

Thirty-nine very preterm neonates were admitted to the neonatal intensive care unit (NICU) of Fukushima Medical University Hospital between October 2008 and March 2010. Although all 39 neonates satisfied the indication for arterial catheter insertion, one neonate who was not able to cannulate was excluded from our study. A peripheral arterial catheter was inserted into 19 neonates (peripheral group) and an umbilical arterial catheter into the remaining 19 neonates (umbilical group) ; the research group did not have any control over the assignment. The chief physician decided the insertion artery each time. Among the 38 very preterm neonates enrolled in this study, 36 were less than 28 weeks and 2 were discordant twins, as determined by fetoscopic laser photocoagulation for TTTS during the fetal period. All these neonates were born in our hospital and had no major cardiac anomaly, and they received vitamin $\mathrm{K}$ at $1 \mathrm{mg} / \mathrm{kg}$ body weight immediately after birth. Small amounts of noninfectious human milk were fed through a nasogastric tube within the first $12 \mathrm{~h}$ of life and continued every $3 \mathrm{~h}$. Ultrasonography of the brain, heart and kidney was performed more than three times every day during the first week of life. Data were collected from perinatal case records. Informed consent for arterial catheter insertion was obtained from the parents on admission. This study was approved by the Ethics Committee of the Fukushima Medical University School of Medicine (number 1184).

\section{Arterial catheter management}

There are two methods of arterial catheter management. The catheterization procedure was as follows. The Allen test ${ }^{5)}$ was performed to assess adequate collateral flow to the entire hands or feet in each neonate. After the skin was disinfected with isodine, a 24-gauge catheter $\left(\right.$ TERUMO $^{\circledR}$ ) with an outer diameter of $0.7 \mathrm{~mm}$ was inserted into an artery under direct vision with the aid of a transilluminator ${ }^{2)}$. The umbilical catheter was 3.5Fr $\left(\right.$ Argyle $\left.^{\circledR}\right)$ with an outer diameter of 1.17 $\mathrm{mm}$. The catheter was inserted by house officers using a standard procedure, and its length was determined on the basis of shoulder-to-umbilicus length ${ }^{6,7)}$. The catheter tip was positioned at the level of the first and fourth lumbar vertebrae ${ }^{8)}$; this was confirmed by X-ray examination and adjusted to the desired level as necessary. The incision site was kept covered and cleaned as much as possible. 
The heparin solution used contained $1 \mathrm{U} / \mathrm{ml}$ heparin $\left(\mathrm{AJINOMOTO}^{\circledR}\right)$ in normal saline including $0.9 \% \mathrm{NaCl}^{9)}$ and was infused at a rate of $0.3 \mathrm{ml} / \mathrm{h}$. Flushing using the same solution was carried out after sampling for blood gases in the umbilical catheter. In the case of the peripheral line, the solution was infused at $0.5 \mathrm{ml} / \mathrm{h}$.

Use of the catheter was discontinued under the following conditions ; 1) persistent skin blanching or erythema over the catheter tip ; 2) discoloration of the fingers and feet ; 3 ) clot formation manifested by inability to withdraw blood or loss of the BP tracing; or 4) leakage around the insertion site. When the catheter was removed, firm pressure was applied to the insertion site with a sterile gauze pad for approximately 5 min to ensure hemostasis.

\section{Statistical analyses}

The variables we analyzed were the characteristics of neonates [sex, GA, BBW, SGA, plurality, mode of delivery, umbilical arterial $\mathrm{pH}(\mathrm{UmApH})$, Apgar score, BT on admission, prenatal steroid usage, chorioamnionitis (CAM)], vital signs [time of catheterization after birth, BT during catheterization, heart rate (HR), and systolic and diastolic BP at catheterization], and clinical courses [respiratory distress syndrome (RDS), urinary output, the doses of dopamine (DOA), hydrocortisone (HDC) and morphine, patent ductus arteriosus (PDA) courses (natural closure or ligation), enteral feeding reaching 50 $\mathrm{ml} / \mathrm{kg} /$ day, necrotizing enterocolitis (NEC), IVH, total time during catheterization, and unplanned catheter withdrawal]. All statistical analyses were performed using Dr. SPSS II for Windows. To examine differences between peripheral and umbilical groups, the Mann-Whitney U test was used for continuous variables and the chi-square test for categorical variables. Correlations between continuous variables were determined using Spearman's rank correlation. Multivariate median regression analysis was performed to further determine an association between BP and urinary output with adjustment for GA. Statistical significance was defined as $p<0.05$.

\section{RESULTS}

\section{Clinical characteristics of 38 neonates}

The 38 neonates consisted of 25 singletons and 13 twins. There were 16 female neonates in this study. The median GAs of the peripheral group and umbilical group were 195 days (range: 169-214) and 185 days (range: 161-196), respectively $(p=0.04)$. The median BBWs of the peripheral group and umbilical group were $716 \mathrm{~g}$ (range : 3561,618 ) and $790 \mathrm{~g}$ (range : 420-1,020), respectively $(p=0.94)$. Thirty-six neonates were born by cesarean section. Table 1 shows the characteristics of the two study groups; which confirmed their similarities. The prenatal steroid usage ratios were the same and not significantly associated with CAM (staged by Blanc ${ }^{10)}$ ) in the two groups.

\section{Blood access}

The following peripheral arteries were catheterized: ulnar, $8(42.1 \%)$; dorsalis pedis, 5 (26.3\%) ; posterior tibial, 4 (21.1\%) ; radial, 2 (10.5 $\%)$. In 9 neonates $(47.4 \%)$, the catheter was inserted into the postductal artery.

\section{Vital signs at catheterization}

Table 2 shows the vital signs at catheterization in the two groups. There were no significant differences in the time of catheterization after birth, the BT during catheterization and $\mathrm{HR}$ at the inserted arterial catheter between the two groups. However, both the systolic and diastolic BPs were significantly higher in the peripheral group than in the umbilical group $(p=0.02$ and 0.001 , respectively).

\section{Clinical courses}

Table 3 shows the clinical courses of the two groups. The median urinary outputs in the peripheral group and umbilical group were $3.6 \mathrm{ml} / \mathrm{kg} /$ day (range : $0.1-6.9$ ) and $1.9 \mathrm{ml} / \mathrm{kg} /$ day (range : 0.1-5.5), respectively $(p=0.03)$. There was no significant difference in the dose of DOA, HDC, or morphine 24 $\mathrm{h}$ after cannulation, and the incidences of PDA natural closure and operation for symptomatic PDA were the same. Both groups showed similar courses in the duration of enteral feeding reaching $50 \mathrm{ml} / \mathrm{kg} /$ day, and there were no neonates with NEC in the two groups. None of the neonates received total parenteral nutrition (TPN) $24 \mathrm{~h}$ after catheterization. There were two neonates with severe IVH (Papile grade $\mathrm{III}^{\circ}$ or $\mathrm{IV}^{\circ}$ ) in the peripheral group. The median durations of catheter indwelling were similar, and the numbers of neonates withdrawn from the planned strategy in the peripheral group and the umbilical group were 6 and 4, respectively.

\section{Relationships of BP with GA and urinary output}

There was a significant relationship between 
Table 1. Comparison of characteristics between peripheral and umbilical artery groups

\begin{tabular}{cccc}
\hline & Peripheral & Umbilical & \\
\cline { 2 - 4 } & $(N=19)$ & $(N=19)$ & $p$ value \\
\hline sex (female) & $8(42 \%)$ & $8(42 \%)$ & 1.00 \\
GA (days) & $195(169-214)$ & $185(161-196)$ & $0.04^{*}$ \\
BBW (g) & $(24 \mathrm{w} 1 \mathrm{~d}-30 \mathrm{w} 4 \mathrm{~d})$ & $(23 \mathrm{w} 0 \mathrm{~d}-28 \mathrm{w} 0 \mathrm{~d})$ & \\
SGA & $716(356-1,618)$ & $790(420-1,020)$ & 0.94 \\
plurality (multiple birth) & $4(21 \%)$ & $2(11 \%)$ & 0.22 \\
mode of delivery & $7(37 \%)$ & $6(32 \%)$ & 0.74 \\
(cesarean delivery) & $19(100 \%)$ & $17(89 \%)$ & 0.36 \\
UmApH & & & 0.39 \\
Apgar Score (5 min) & $8.318(6.621-7.414)$ & $7.360(6.928-7.457)$ & 0.38 \\
BT on admission $\left({ }^{\circ} \mathrm{C}\right)$ & $36.0(35.0-37.9)$ & $8(2-9)$ & 1.00 \\
prenatal steroid usage & $9(47 \%)$ & $95.9(34.4-37.0)$ & -- \\
CAM (Yes) & $8(42 \%)$ & $9(47 \%)$ & \\
(No, I, II, III, NE) & $(11,1,2,1,4)$ & $(10,1,3,3,2)$ & \\
\hline
\end{tabular}

${ }^{*} p$ value $<0.05$. The Mann-Whitney $\mathrm{U}$ test was used for continuous variables and the chisquare test for categorical variables.

CAM (staged by Blanc) : No, none ; I, intervillositis ; II, chorionitis ; III, chorioamnionitis ; NE, not examined.

Table 2. Vital signs at catheterization

\begin{tabular}{cccc}
\hline & Peripheral & Umbilical & $p$ value \\
\hline time of catheterization after birth $(\mathrm{h})$ & $3.0(1.5-10.5)$ & $2.5(1.5-4.0)$ & 0.24 \\
BT before catheterization $\left({ }^{\circ} \mathrm{C}\right)$ & $36.5(34.9-37.8)$ & $36.6(34.3-37.4)$ & 0.79 \\
after catheterization $\left({ }^{\circ} \mathrm{C}\right)$ & $36.8(35.5-38.6)$ & $37.0(34.4-37.9)$ & 0.75 \\
& & & \\
heart rate $(/ \mathrm{min})$ & $154(124-184)$ & $152(136-182)$ & 0.75 \\
systolic BP $(\mathrm{mmHg})$ & $40(28-56)$ & $32(16-66)$ & $0.02^{*}$ \\
diastolic BP $(\mathrm{mmHg})$ & $26(20-32)$ & $16(8-44)$ & $0.001^{*}$ \\
\hline
\end{tabular}

${ }^{*} p$ value $<0.05$. The Mann-Whitney $\mathrm{U}$ test was used for continuous variables

$\mathrm{GA}$ and $\mathrm{BP}$ at catheterization in the peripheral and umbilical groups with correlation coefficients $\left(r_{\mathrm{s}}\right)$ of $0.48(p=0.04)$ and $0.47 \quad(p=0.04)$, respectively (Figure 1). As for association between BP and urinary output within each group, there was an apparent correlation in the peripheral group $\left(r_{\mathrm{s}}=0.49\right.$, $p=0.03$ ) (Figure 2), but the statistical significance diminished when adjusted for GA (regression coefficient $=0.11, p=0.12$.

\section{Complications associated with arterial catheter man- agement}

Six neonates (16\%) developed complications associated with arterial catheter management. Two neonates had umbilicus accidents due to hemorrhage or unsuccessful ligature, and two neonates had high levels of gastric residues in the umbilical group. Two neonates showed $\mathrm{C}$ reactive protein (CRP) levels higher than $5 \mathrm{mg} / \mathrm{dl}$ in the peripheral group. None of the neonates developed thromboembolism.

\section{DISCUSSION}

Arterial catheterization is a common practice in NICU, which is part of the routine management of high-risk neonates, and reduces distress by reducing the need for vein puncture and heel cut capillary 
Table 3. Clinical courses in the two groups

\begin{tabular}{cccc}
\hline & Peripheral & Umbilical & $p$ value \\
\hline RDS & $15(79 \%)$ & $14(74 \%)$ & 0.71 \\
urinary output $(\mathrm{ml} / \mathrm{kg} / \mathrm{h})$ & $3.6(0.1-6.9)$ & $1.9(0.1-5.5)$ & $0.03^{*}$ \\
DOA $(\mu \mathrm{g} / \mathrm{kg} / \mathrm{min})$ & $1.7(0-5.9)$ & $1.7(1.4-3.5)$ & 0.63 \\
HDC $(\mathrm{mg} / \mathrm{kg})$ & $1.5(0-6.2)$ & $3.0(0-5.2)$ & 0.05 \\
morphine $(\mu \mathrm{g} / \mathrm{kg} / \mathrm{min})$ & $6.5(0-9.6)$ & $7.2(0-7.6)$ & 0.47 \\
PDA natural closure & $7(37 \%)$ & $7(37 \%)$ & 1 \\
PDA ligation & $3(16 \%)$ & $3(16 \%)$ & 0.44 \\
enteral feeding reaching 50 & $9(5-16)$ & $8(6-12)$ & - \\
ml/kg/day & 0 & 0 & 0.15 \\
NEC & $2(11 \%)$ & 0 & 0.75 \\
IVH (Papile grade III ${ }^{\circ}$ or IV $\left.{ }^{\circ}\right)$ & $141(70-241)$ & $137(86-240)$ & 0.47 \\
total time in place $(\mathrm{h})$ & $6(32 \%)$ & $4(21 \%)$ & \\
unplanned withdrawal & & & \\
\hline
\end{tabular}

${ }^{*} p$ value $<0.05$. The Mann-Whitney $\mathrm{U}$ test was used for continuous variables and the chi-square test for categorical variable.

Urinary output was measured $24 \mathrm{~h}$ after catheterization.

DOA and morphine were at their maximum dose $24 \mathrm{~h}$ after catheterization.

$\mathrm{HDC}$ is shown as total dose $24 \mathrm{~h}$ after catheterization.
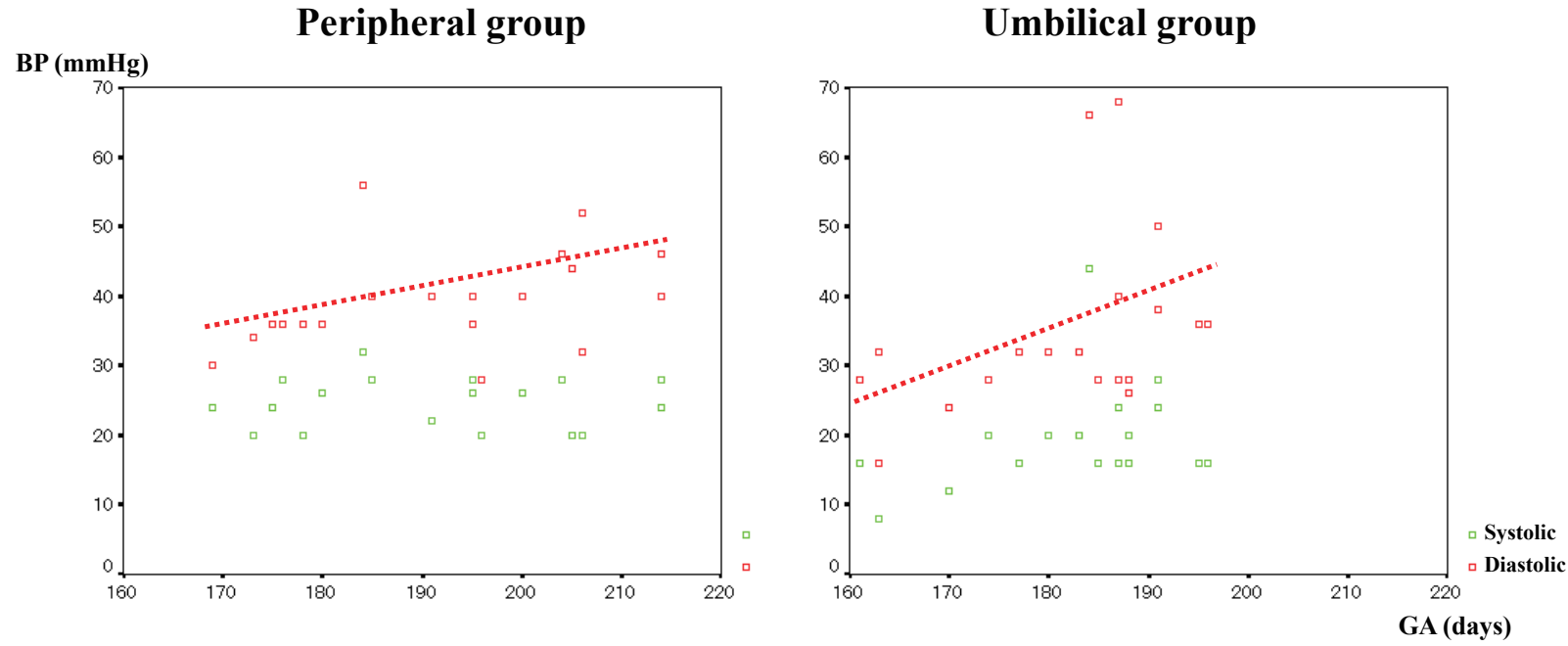

$r_{\mathrm{s}}(p$ value)

\begin{tabular}{lcc} 
& \multicolumn{2}{c}{$r_{\mathrm{s}}(p$ value $)$} \\
\cline { 2 - 3 } & GA/ Systolic BP & GA/ Diastolic BP \\
\hline Peripheral group & $0.48(0.04 *)$ & $0.13(0.61)$ \\
Umbilical group & $0.47(0.04 *)$ & $0.35(0.14)$ \\
\hline & & $* p<0.05$
\end{tabular}

Fig. 1. Relationship between GA and BP

There were correlations between GA and systolic BP in the peripheral group and umbilical group. The $r_{\mathrm{s}}(p$ value) values in the peripheral group and umbilical group were $0.48(0.04)$ and $0.47(0.04)$, respectively.

blood sampling in very preterm neonates. Peripheral arteries may be difficult to cannulate because of their small size, vasoconstriction due to hypotension, or multiple previous punctures at the site in very preterm neonates, whereas serious damage appears to be rare, because peripheral isch- 
Urine $(\mathrm{ml} / \mathrm{kg} /$ day)

\section{Peripheral group}

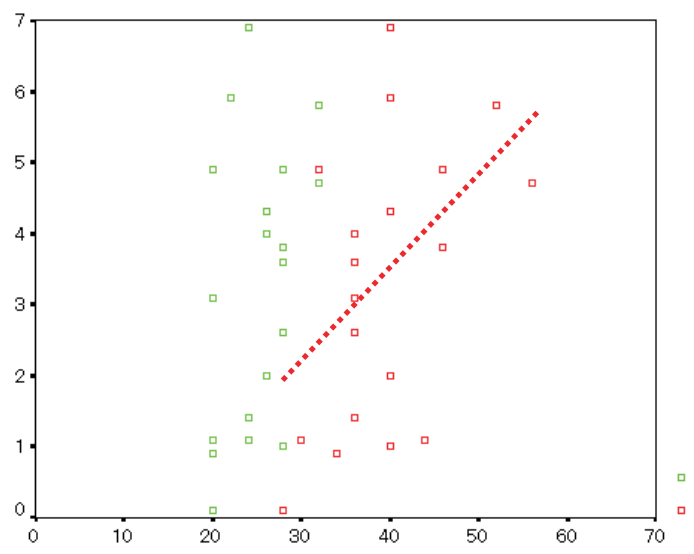

Umbilical group

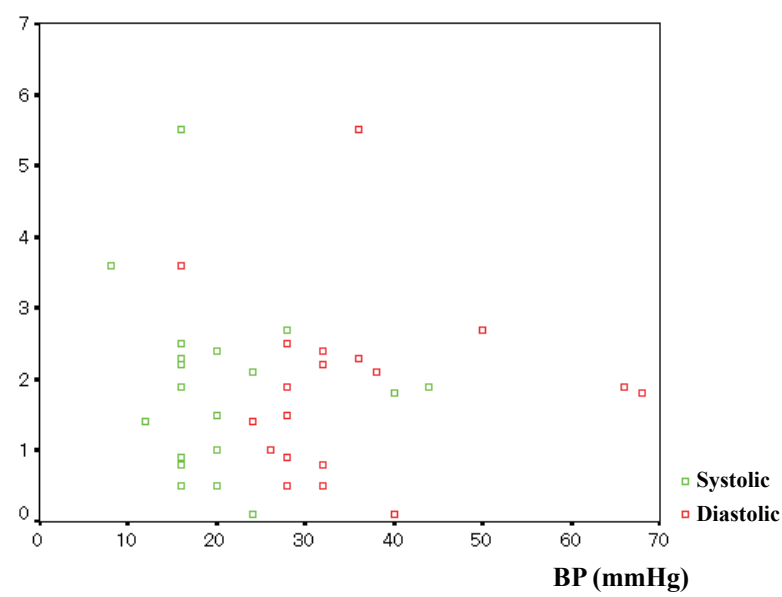

$r_{\mathrm{s}}(p$ value $)$

\begin{tabular}{lcc} 
& \multicolumn{2}{c}{$r_{\mathrm{s}}(p$ value $)$} \\
\cline { 2 - 3 } & Systolic BP/ Urine & Diastolic BP/ Urine \\
\hline Peripheral group & $0.49(0.03 *)$ & $0.32(0.18)$ \\
Umbilical group & $0.10(0.69)$ & $-0.14(0.57)$ \\
\hline
\end{tabular}

$* p<0.05$

Fig. 2. Relationship between BP and urinary output There were correlation between systolic BP and urinary output after catheterization during $24 \mathrm{~h}$ in the peripheral group $\left(r_{\mathrm{s}}=0.49, p=0.03\right)$, however no such correlation was found in the umbilical group.

emia may be detected immediately ${ }^{11,12)}$. In contrast to umbilical arterial catheterization, there were many potential complications such as arterial thromboses, NEC associated with this management, and aortic wall vascular complications in animal models of extreme prematurity have been reported ${ }^{13,14)}$.

Murdoch et $a{ }^{15}{ }^{15}$ found a positive correlation between GA and superior mesenteric artery (SMA) pulsatility index and a negative correlation between GA and end-diastolic flow on the first day of life ; it is possible that these Doppler indices vary with GA because of the effects of other factors, such as circulatory blood volume or BP. Therefore, we speculated that renal arterial flow might also be influenced by GA or BP. Butt and Whyte ${ }^{16)}$ reported that peripheral arterial BP correlates well with umbilical arterial BP in neonates with different weights, GA, and underlying stressors on therapies as well as adaptation to the extrauterine system. In this study, we examined urinary output as an indicator of circulatory monitoring in the first few days of life. Urinary output after catheterization during 24 $\mathrm{h}$ in the peripheral group was much higher than that in the umbilical group. This was associated with $\mathrm{BP}$ at cannulation in the peripheral group ; however, no such association was found in the umbilical group. This may indicate that first, urinary output in early life is affected by GA, because the neonates in the peripheral group were more mature than those in the umbilical group, and there were no significant differences in the clinical courses between the two groups. Second, the umbilical catheter was placed at a low position (at the level of the twelfth thoracic vertebrae and third lumbar vertebrae) in this study, which might have affected renal flow, because the renal artery almost diverges from the aorta at the level of the first and second lumbar vertebrae $^{17)}$. Rand et $a l .{ }^{18)}$ reported that the SMA flow velocity before the removal of the umbilical arterial catheter is lower than that after the removal of the catheter; however, to the best of our knowledge, there was no report of the evaluation of the changes in renal arterial circulation caused by the inserted umbilical arterial catheter. Surveillance of blood flow velocity in renal arteries should be considered in the case of umbilical catheter placement.

There were no significant differences in the duration of enteral feeding reaching $50 \mathrm{ml} / \mathrm{kg} /$ day in each group. However, Randel et al. ${ }^{19)}$ reported that enteral feeding is often withheld while the umbilical 
catheter is in place, whereas the use of a peripheral arterial catheter prevents the delay in feeding. On the other hand, Havranek et al. ${ }^{20)}$ reported that the umbilical artery catheter does not affect intestinal blood flow during minimal enteral feeding. TPN may be a stressor because it is contaminated with products of photo-oxidation including peroxides, which are mediators in complex mechanisms of vasomodulation $^{21-23)}$. Although Chessex et al. ${ }^{24)}$ reported that failure to shield TPN from light results in a higher blood pressure in selected critically ill female neonates, none of the neonates received TPN $24 \mathrm{~h}$ after catheterization in this study.

Two neonates had severe IVH in the peripheral group, and they died with a CRP level of more than $5 \mathrm{mg} / \mathrm{dl}$ in the neonatal period. One neonate was SGA with a BBW of $356 \mathrm{~g}$, and the other had CHD and required anticoagulant management for hyperammonemia (maximum ammonia level : 1,683 $\mu \mathrm{g} /$ dl). It was very difficult to assess the association of infection with peripheral arterial catheter management and identify the source of infections, because both neonates were in very poor condition. Many cases of complications in the acute phase caused by the inserted arterial catheter have been reported; however, there are no long-term follow-up studies of the safety of arterial catheter management, which are necessary for evaluating the growth prognosis including extremity growth and neurologic status in the future.

Our study has two major limitations. First, the indication for the placement of the peripheral or umbilical artery catheter in neonates did not set in our hospital. Therefore, observed differences between the two groups might have been caused by characteristics of neonates rather than the difference in the arterial catheter management. Second, we did not regularly perform a renal flow study by ultrasonography after insertion of the umbilical catheter. Along with the small sample size and abovementioned nonrandomized study design, it was difficult to conclude whether umbilical catheter placement affected urinary output in this study.

Taken together, we considered that peripheral arterial catheters provide a well-functioning route for continuous BP monitoring, even in very preterm neonates, and can be a reliable alternative to umbilical arterial catheters under meticulous care. Moreover, urinary output after cannulation during $24 \mathrm{~h}$ in the peripheral group was much higher than that in the umbilical group. Because it is considered that umbilical catheter placement might affect renal flow, we speculated that peripheral arterial catheter placement would be a more effective management strategy than umbilical arterial catheter placement in very preterm neonates. Further studies of larger populations are necessary to evaluate the effectiveness of arterial catheter management including long-term follow-up studies.

\section{ACKNOWLEDGEMENTS}

The authors are grateful to the members of the Department of Pediatrics for their valuable advice and comments on this study.

\section{REFERENCES}

1. Olinger GN, Mulder DG. Direct monitoring of arterial blood pressure in the newborn and infant: A difficult procedure made easy. Ann Thorac Surg, 21 : 557-559, 1976.

2. Pearse RG. Percutaneous catheterization of the radial artery in newborn babies using transillumination. Arch Dis Child, 53 : 549-554, 1978.

3. Kramer MS, Platt RW, Wen S, Joseph KS, Allen A, Abrahamowicz M, Blondel B, Breart G; Fetal/ infant Health Study Group of the Canadian Perinatal Surveillance System. A new and improved population-based Canadian reference for birth weight for gestational age. Pediatrics, 108 : E35, 2001.

4. Papile LA, Burstein J, Burstein R, Koffler H. Incidence and evolution of subependymal and intraventricular hemorrhage: A study of infants with birthweight less than 1500 gram. J Pediatr, 92 : 529, 1978.

5. Allen EV. Thromboangitis obliterans. Methods of diagnosis of chronic occlusive arterial lesions distal to the wrist with illustrative cases. Am J Med Sci, 178 : 237-244, 1929.

6. Dunn PM. Localization of the umbilical catheter by post-mortem measurement. Arch Dis Child, 41: 69-75, 1966.

7. Lopriore E, Verheij GH, Walther F. Measurement of the 'shoulder-umbilical' distance for insertion of umbilical catheters in newborn babies : questionnaire study. Neonatology, 94 : 35-37, 2008.

8. Butt WW, Gow R, Whyte H, Smallhorn J, Koren G. Complications resulting from use of arterial catheters : retrograde flow and rapid elevation in blood pressure. Pediatrics, 76 : 250-254, 1985.

9. Butt W, Shann F, McDonnell G, Hudson I. Effect of heparin concentration and infusion rate on the patency of arterial catheters. Crit Care Med, 15 : 230-232, 1987.

10. Blanc WA. Pathology of the placenta, membranes, and umbilical cord in bacterial, fungal, and 
viral infections in ma. Monogr Pathol, 22 : 67$132,1981$.

11. Sellden H, Nilsson K, Larsson LE, Ekstrom-jodal B. Radial arterial catheters in children and neonates: A prospective study. Crit Care Med, 15 : 1106-1109, 1987.

12. Ramasethu J. Complications of vascular catheters in the neonatal intensive care unit. Clin Perinatol, 35 : 199-222, 2008.

13. Caeton AJ, Goetzman BW. Risky business. Umbilical arterial catheterization. Arch Dis Child, 139 : 120-121, 1985.

14. McAdams RM, Winter VT, McCurnin DC, Coalson JJ. Complications of umbilical artery catheterization in a model of extreme prematurity. J Perinatol, 29 : 685-692, 2009.

15. Murdoch EM, Sinha AK, Shanmugalingam ST, Smith GC, Kempley ST. Doppler flow velocimetry in the superior mesenteric artery on the first day of life in preterm infants and the risk of neonatal necrotizing enterocolitis. Pediatrics, 118 : 1999-2003, 2006.

16. Butt WW, Whyte H. Blood pressure monitoring in neonates: Comparison of umbilical and peripheral artery catheter measurements. J Pediatr, 105 : 630-632, 1984.

17. Standring S. The anatomical basis of clinical practice. In : Mundy AR, ed. Posteromedial surface of both kidneys. GRAY'S Anatomy, ed 39, Philadelphia, 1272, 2005.

18. Rand T, Weninger M, Kohlhauser C, Bischof S,
Heinz-Peer G, Trattnig S, Popow C, Salzer HR. Effects of umbilical arterial catheterization on mesenteric hemodynamics. Pediatr Radiol, 26 : 435438, 1996.

19. Randel SN, Tsang BH, Wung JT, Driscoll JM Jr, James LS. Experience with percutaneous indwelling peripheral arterial catheterization in neonates. Am J Dis Child, 141 : 848-851, 1987.

20. Havranek T, Jophanboeke P, Madramootoo C, Carver JD. Umbilical artery catheters do not affect intestinal blood flow responses to minimal enteral feedings. J Perinatol, 27 : 375-379, 2007.

21. Neuzil J, Darlow BA, Inder TE, Sluis KB, Winterbourn CC, Stocker R. Oxidation of parenteral lipid emulsion by ambient and phototherapy lights: potential toxicity of routine parenteral feeding. J Pediatr, 126 : 785-790, 1995.

22. Lavoie JC, Bélanger S, Spalinger M, Chessex P. Admixture of a multivitamin preparation to parenteral nutrition: the major contributor to in vitro generation of peroxides. Pediatrics, 99 : E61-70, 1997.

23. Walsh SW, Wang Y, Jesse R. Peroxide induces vasoconstriction in the human placenta by stimulating thromboxane. Am J Obstet Gynecol, 169 : 1007-1012, 1993.

24. Chessex P, Khashu M, Harrison A, Hosking M, Sargent M, Lavoie JC. Early life events, sex, and arterial blood pressure in critically ill infants. Pediatr Crit Care Med, 11 : 75-81, 2010. 